\title{
Discovering and Developing Diverse STEM Talent: Enabling Academically Talented Urban Youth to Flourish
}

by Stephanie Pace Marshall, Glenn W. "Max" McGee, Eric McLaren, and Catherine C. Veal 
I daydream of speeding through unknown galaxies to discover planets unknown. I travel to the ends of the universe, observing its simple yet beautiful extravagancies... I master the beautiful and delicate intricacies of time and space. I explore the most intriguing and mystifying forms of a star, a "Blackhole". . becoming the greatest scientist there ever was.

Who daydreams like this? A 13-year-old African American boy, academically talented in mathematics and science, living and learning in East St. Louis, IL, as noted on his application essay.

Reignited by the urgency of the National Academy of Sciences, the National Academy of Engineering, and the Institute of Medicine's (2007) report Rising Above the Gathering Storm, our nation has escalated its commitment and targeted resources to develop science, technology, engineering, and mathematics (STEM) talent and improve STEM education. Unparalleled global competition for intellectual capital and the ease of talent transfer has catapulted STEM research and innovation to the top of our national agenda, and our President has now called us to "Educate to Innovate" (Obama, 2009).

The United States is not alone. Talent development and innovation are at the center of most nations' global strategies for sustainable prosperity. These converging contexts provide both the impetus and the imperative for ensuring our children acquire the knowledge, skills, and habits of mind essential to advance the 21 st-century STEM frontier.

Nowhere is the need for advanced and innovative STEM education more acute than in the education of our nation's gifted and talented students in mathematics, science, and technology.
Nowhere are the challenges greater and more far-reaching than those presented by academically talented urban youth who are often high-achieving and economically disadvantaged. Wyner, Bridgeland, and Dilulio (2007) noted that these students

face significant obstacles to continuing their high levels of achievement . . . disproportionately fall out of the high-achieving group during elementary and high school ... and perhaps most disturbingly, far too few ever graduate from college or go on to graduate school. (p. 4)

In their report Mind the (Other) Gap! The Growing Excellence Gap in K-12 Education, Plucker, Burroughs, and Song (2010) provided compelling evidence that "the presence of an excellence gap is demonstrated on both national and state assessments of student performance," with "economically disadvantaged, English Language Learners, and historically underprivileged minorities representing a smaller proportion of students scoring at the highest levels of achievement" (p. 28). The report concludes that since 2003 this excellence gap has been "stable or growing," with overrepresented, more advantaged groups "generally increasing their performance" while academic scores of more underrepresented, less advantaged groups "stagnated or increased slightly" (Plucker et al., 2010, p. 28). Our nation cannot permit geography or demography to determine destiny.

Although the challenges confronted by talented urban youth, especially those in underresourced communities, are historically embedded and persistent, highly successful programs exist that can serve as models for discovering and developing diverse STEM talent.
By design, we can create conditions that enable academically talented urban youth to flourish. This article describes the work of one such program, the Illinois Mathematics and Science Academy (IMSA, n.d.). Three "case stories" of students from IMSA illuminate some of the (a) challenges and opportunities inherent in igniting STEM talent in urban youth and ensuring their success; (b) principles for designing and creating learning experiences and environments that ignite and nurture the development of "creative, ethical scientific minds" (IMSA, 2009); and (c) institutional lessons that have become clear to us after more than two decades of developing diverse STEM talent.

These stories cannot be viewed as representative of academically talented urban youth. Each student's unique constellation of talents reflects the complex integration of his or her cultural, parental, social, and formal and informal learning contexts. Rather, they anchor our reflections and serve as authentic contexts for the IMSA design.

\section{Meet Miguel, Lynn, and Terez}

Miguel Garcia is a current IMSA student from Aurora, the second largest city in Illinois, where his high school enrollment is $84 \%$ Hispanic and $70 \%$ low income. Alumna Lynn Sosa from Chicago first applied to IMSA 3 years after then-Education Secretary William Bennett called the Chicago Public Schools the "worst in the nation" (Chicago Public Schools, 2010). She is now a physician working in public health. Alumnus Terez Ivy grew up in East St. Louis, IL, one of the most economically and educationally impoverished regions of the country, profiled in Jonathan Kozol's (1991) book Savage Inequalities: Chil- 
dren in America. At that time, Terez's hometown was known for dilapidated housing, high unemployment, crime, gangs, poor health care, polluted air, and schools with countless problems including 30- to 50-year-old science labs (Kozol, 1991). Today, Terez leads new product design and systems integration for a leading IP telephony systems integrator. Here are their stories.

\section{Miguel Garcia}

\section{No one's path in life is predetermined. —IMSA (2009, para. 1)}

Miguel demonstrated talent in elementary school. As a fourth grader, he participated in Junior/Senior Scholars, an outreach program of North Central College in Naperville, IL. This program brought children from his elementary school to a 6-week summer day camp at the college. Working with college students as mentors and participating in stimulating field trips throughout the Chicago area not only introduced Miguel and his classmates to new experiences, but also opened their eyes to the possibilities of a future not defined by their current circumstances. Through immersion in dynamic learning experiences, Miguel began to realize that his path in life was not predetermined.

Two years later, he learned of IMSA through connections in his community-a friend's older brother, a neighborhood "buddy," and most importantly, a teacher who recommended that as a sixth grader, Miguel participate in the IMSA FUSION program, an afterschool enrichment program for students "talented, interested and motivated in mathematics and science, with special emphasis on students historically underrepresented and underserved in these areas" (IMSA, 2010, para. 1).

In IMSA FUSION, Miguel expe-

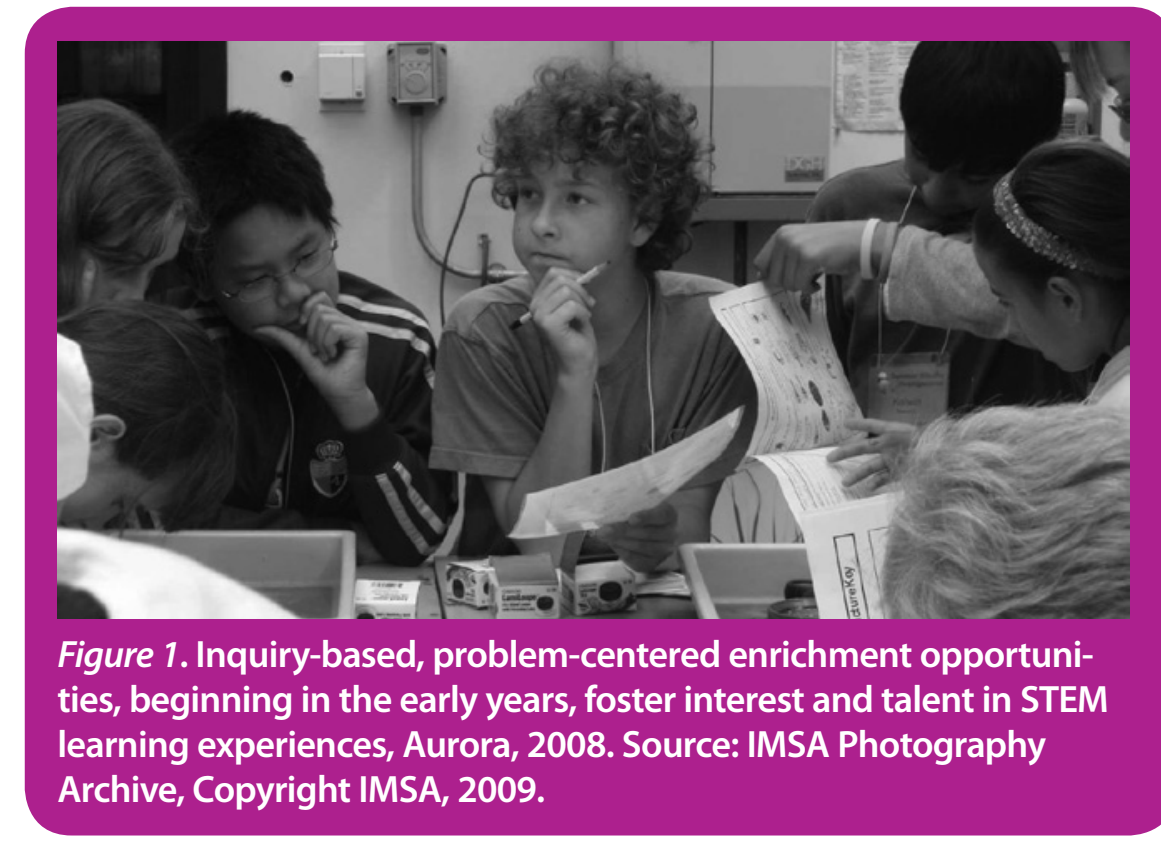

rienced "real science" in a way that was entirely new to him; in "school science," he had quickly completed his work only to be given more worksheets, told to read, or asked to help "slower" students. In IMSA FUSION he thrived, challenged by hands-on experiments, active discussions with other students, and engaging dialogue with his teachers and parents. These experiences not only advanced his knowledge and skills, but also motivated him to excel and seek further IMSA opportunities (see Figure 1).

Miguel enrolled in IMSA's Summer Enrichment Academics in Mathematics and Science (SEAMS), a 2-week residential program, where he was again actively engaged in real science and found great delight in "blowing something to smithereens." His curiosity and interest ignited, he was now convinced he wanted to attend IMSA.

Miguel encountered a host of unintended, yet very real, challenges in the admission process: no home computer, navigating through SAT registration, peer pressures, limited English at home, and even a few lessthan-supportive teachers. Regrettably, for many talented urban youth, lack of teacher encouragement and support and erroneous preconceptions of ability diminish their self-confidence and frequently discourage and inhibit them from proactively seeking advanced learning opportunities, developing their potential, and strongly presenting themselves in competitive admissions processes.

Yet Miguel persisted. With support from several advocates, he registered for the SAT and handwrote the IMSA application, which included five essay questions. He selected the IMSA (2009, para. 1) belief statement, "No one's path in life is predetermined," penning a compelling autobiographical statement:

I come from a school that is not too high in academics and is always being criticized because of that ... a lot of people tell me that I cannot go very far coming from that school. That is not true, however, and as long as I work hard enough, I can achieve anything.

Miguel was admitted and participated in a 3-week preenrollment residential summer program, EXCEL, to strengthen his academic skills and 
deepen his engagement in inquirybased and problem-centered learning. Miguel is succeeding academically; building a diverse, closely knit peer group; staying connected with his family, friends, and home community; and embodying his belief that "with hard work, I can achieve anything" (M. Garcia, personal communication, October 13, 2009).

\section{Lynn Sosa}

I learned by seeing how it works. I realized this is how learning happens.

The first time she applied to IMSA, as an eighth grader (a year earlier than most applicants), Lynn Sosa was not admitted. Undeterred, she applied again and was admitted. For Lynn, a Chicago magnet school student, science was always a "natural interest." She and her three brothers, two of whom also attended IMSA, benefited from "proactive parent support" (both parents were educators). "They enrolled us in summer programs in areas of science I naturally gravitated towards," she said. One example was a summer program at the Illinois Institute of Technology in fourth or fifth grade, where she was introduced to microbiology.

Lynn also attended IMSA's Summer Ad'Ventures program, calling it a "key learning experience," adding, "I could see IMSA was a different place." She enjoyed the social setting and saw IMSA as a great opportunity to "fit in to a peer group of like-minded students" and sustain relationships with other talented students. Attending magnet schools in Chicago had constrained her opportunities to interact with academic peers beyond the school day. The residential nature of IMSA was compelling to Lynn.

At IMSA, she loved the array of science classes and cited Microbiol- ogy as most influential. "I had early experiences doing hands-on lab work in the field and ended up loving it," she said. Today she works in a medical clinic for treating sexually transmitted diseases. "I am still running Gram stains that I learned at IMSA and, even now, still love it," she said. She also took Pathogenic Microbiology at IMSA, which fostered her interest in infectious diseases: "Patho was really cool, and I could see myself doing it."

After IMSA, Lynn pursued her study of infectious diseases at Harvard Medical School and had a fellowship at the Centers for Disease Control and Prevention. After residency, she realized "public health made sense for me... I wanted to make a difference."

Lynn credits IMSA with preparing her for how to learn and for Harvard Medical School, where, like at IMSA, "I was in charge of my own learning." She said the IMSA classes in which she was most successful "forced me to apply my own learning on papers, problem sets, and in labs . . . labs forced me to do it for myself, rather than listening to lectures [see Figure 2]. I learned by seeing how it works. I realized this is how learning happens" (L. Sosa, personal communication, November 24, 2009).

\section{Terez Ivy}

Understand the concepts at their heart and know the beauty they manifest.

Our 13-year-old astronomical daydreamer, whose hobbies were modeling and designing high-speed aircraft, was the youngest member of his high school freshman class when he applied to attend IMSA "for the experience of going beyond the ordinary and of crossing over the threshold to the extraordinary."

Today, Terez is a systems architect for the leading integrator of IP telephony systems in the Washington, DC, metro area and the "go-to guy" for new product design and systems integration. Previously he worked as a software engineer at Lockheed Martin.

Terez's interest in mathematics and

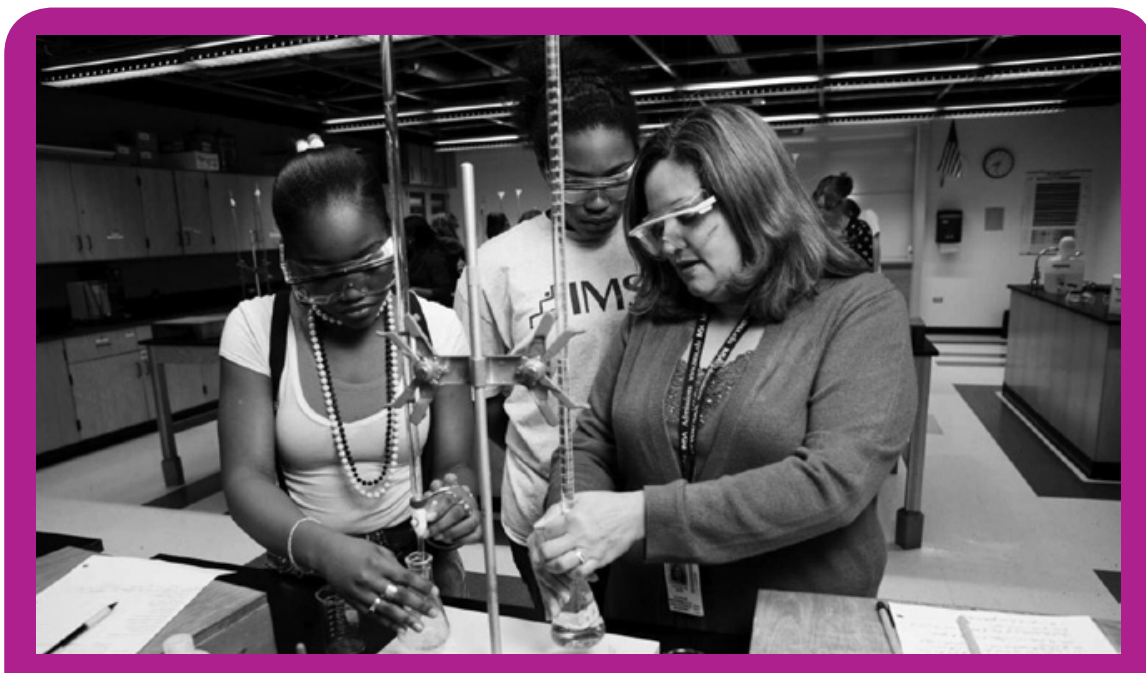

Figure 2. All first-year IMSA students enroll in the Methods of Scientific Inquiry course, which shapes the nature and quality of their scientific thinking, Aurora, 2008. Source: Craig Watson Photography, Copyright Craig Watson, 2008. 
science was nurtured at a young age by his mother, a Star Trek fan ("I learned a lot about science and the scientific method by watching that show"); his grandmother, who faithfully watched Dr. Who with him ("He was the personification of everything I wanted to be"); and the director of gifted education for East St. Louis School District 189, who took Terez and other talented East St. Louis youth under her wing, encouraged them to apply to IMSA, and provided extensive support. This intense familial learning exposure and support, coupled with personal mentoring by the district's director of gifted education, was critical to Terez's growth and development in East St. Louis. In a statement by the East St. Louis superintendent of schools made to Kozol in 1991, Dr. Lillian Parks said,

Gifted children are everywhere in East St. Louis, but their gifts are lost to poverty and turmoil and the damage done by knowing they are written off by their society. Many of these children have no sense of something they belong to. They have no feeling of belonging to America. (pp. 33-34)

A postadmission, preenrollment orientation interview revealed important clues about Terez's imagination and motivation. "This student engages in role-playing at a level that I am not familiar with," a staff member wrote. "While waiting for me, he held conversations with Lee Iacocca and W. Clement Stone." While these business icons were not typical "companions" to most 13-year-olds, Stone's rags-to-riches story, use of "a 'positive mental attitude' to make money" and ability to grow " $\$ 100$ in savings into an insurance empire" (Martin, 2002, para. 1) reinforced the dreams Terez held for himself. It was not surprising then, that when asked about his initial reason for applying to IMSA, Terez responded that it was a "great opportunity" and he had a "strong desire not to be poor." Commenting on what she expected her son to receive at IMSA that he would not gain in his home environment, his mother said, "[I want] his mind to be challenged" and "[I want] him to be excited about getting up every day" (C. J. Brown, personal communication, July 20, 1989).

At IMSA, the difference-makers for Terez were the caliber and diversity of his peers, the opportunity to "play" with advanced technology, and the conceptcentered, integrative teaching and learning he found and came to love.

He recalled that being surrounded by other talented teenagers challenged him to think in ways he had never thought before: "We would sit around in Residence Hall '07 and have discussions about grand unification theories and geopolitics until the wee hours of the morning. Who does that at 15?" Living and learning with people from different cultures was a breakthrough experience for Terez, who had lived and attended school in an almost exclusively African American city. $\mathrm{He}$ relished the racial/ethnic, geographic, and socioeconomic diversity of IMSA's student body and the diverse perspectives and ideas he encountered.

$\mathrm{He}$ also benefitted from "exposure and access" to advanced technologies, including the Internet, Apples and PCs, and the supercomputer at the University of Illinois at Urbana-Champaign-rare resources for high school students at the time. Embracing and adjusting to new technologies is easy for Terez today, and he attributes his agility - "I can change on a dime" - to opportunities he had at IMSA to "play with cool learning tools."

Reflecting on the challenges he encountered at IMSA, Terez cited the limited curriculum he had in East St. Louis, especially in comparison to peers who came from well-funded, high- performing schools: "Others had been through algebra and trigonometry. I had less math so I couldn't go as far." Still, he fully embraced the high expectations and rigor of IMSA and went as far as he could, his worldview and sense of self forever altered in the process.

Eighteen years after graduating from IMSA, Terez still recalls the famous mantra of a chemistry teacher: "Conceptualize and internalize; don't memorize and regurgitate." He says this was one of the most useful things he ever learned:

I have realized over the years that if you know the concepts and understand them on a fundamental level, you can look up the details to fill in the gaps, but if you only know something as it applies to a singular instance, it is much harder to extrapolate that to the larger context.

Terez also recalls the "vibrancy" of teaching at IMSA, which for him came from the faculty's deep disciplinary knowledge and their constant reminder to "see the art in the science." This reaffirmed his growing awareness of the "beauty in science" and his belief that "if you understand it, that beauty is reflected in every corner of this physical world."

For him, the essence of IMSA was: "Understand the concepts at their heart and know the beauty they manifest" (T. Ivy, personal communication, November 12, 2009).

\section{Illuminating the "Understory": Learning Conditions That Ignite and Nurture Talent}

Miguel, Lynn, and Terez tell distinct personal narratives of learning and career trajectories. Viewed to- 
gether, through the lens of the IMSA learning culture and academic community they shared, their stories illuminate "mind-shaping" patterns of personal discovery, meaning, efficacy, and transformed learning identities.

IMSA's learning culture and environment enable students to (a) shift the locus of control for learning from others to themselves; (b) become more autonomous, creative, and metacognitive learners; (c) take responsibility for shaping the nature and quality of their own thinking; (d) redefine their learning identity from passive information recipient to active knowledge generator and constructor of their own meaning; (e) develop intellectual discipline, emotional resilience, and confidence to resolve unpredictable dilemmas and solve novel, ill-structured problems; (f) discover their talents, embrace what they love, and become comfortable with who they are; (g) explore the human consequences of innovation and research and actively participate in serving and giving back to others; and (h) develop an expansive and multidimensional worldview.

By design, the IMSA experience enables academically talented urban youth to flourish; to redefine themselves as competent and resilient learners, leaders, innovators, and change agents; to reject externally defined or imposed proxies for success and illusions of achievement; and to find their own voice and claim their own path with confidence and courage.

What is the IMSA design? Table 1 frames four interdependent dimensions of the IMSA system design as a teaching and learning laboratory for imagination and inquiry: (a) learning beliefs we strive to manifest in programs and practice; (b) learning competencies we challenge students to master; (c) learning principles that ground the design of learning experiences; and (d) learning contexts that guide curriculum, instruction, and assessment and design and implementation.

These learning beliefs, competencies, principles, and contexts are manifested in a dynamic program of advanced study characterized by (a) national and international research conferences and competitions and leadership and service opportunities; (b) accelerated and innovative courses, extended mentorships, seminars, and independent study projects; (c) entrepreneurial applied science and technology projects; (d) dialogues with renowned thinkers and leaders; (e) student-led enrichment programming for younger learners; and (f) flexible, creative uses of time, space, and place.

\section{Lessons Learned: What Has Become Clear to Us}

After more than two decades of broad and deep engagement with a diverse cadre of academically talented youth and their families, in both our residential program (grades 10-12) and our statewide student enrichment programs (grades 3-9), we have learned some important lessons about the talent development of urban youth.

\section{Table 1 IMSA, by Design}

Learning Beliefs

Meaning is constructed by the learner.

The ability to discern and create connections is the essence of knowing.

No one's path in life is predetermined.

All people have choices and are responsible for their actions.

Diverse perspectives enrich understanding and inspire discovery and creativity.

Learning never ends.

\begin{tabular}{|c|c|c|}
\hline Learning Competencies & Learning Principles & Learning Contexts \\
\hline $\begin{array}{l}\text { Knowledge, skills, and habits of mind of } \\
\text { an integrative learner and ethical leader }\end{array}$ & Pers & Imagination \\
\hline $\begin{array}{l}\text { - Standards of significant learning: } \\
\text { integrative ways of knowing } \\
\text { Disciplinary standards: deep con- } \\
\text { ceptual understanding } \\
\text { - } \quad \text { Inquiry competencies: creative } \\
\text { problem finding and solving } \\
\text { - } \quad \text { Leadership competencies: advocacy } \\
\text { and action for the common good }\end{array}$ & $\begin{array}{l}\text { - } \quad \text { Curiosity and inquiry } \\
\text { - } \quad \text { Knowledge and meaning construc- } \\
\text { - } \quad \text { Engagement and ownership } \\
\text { - } \quad \text { Exploration and discovery } \\
\text { - } \quad \text { Disciplinary integration } \\
\text { - } \quad \text { Collaboration and trust }\end{array}$ & $\begin{array}{l}\text { - Concept-centered, competency- } \\
\text { driven curriculum } \\
\text { - Problem-centered, inquiry-based } \\
\text { instruction } \\
\text { - Disciplinary, interdisciplinary, and } \\
\text { - } \quad \text { gerformance-based assessment } \\
\text { ogenerative and embedded technol- }\end{array}$ \\
\hline
\end{tabular}


The complexities of "growing up urban," often in conditions of economic deprivation that mitigate high levels of academic achievement and reinforce the masking or denial of academic talent, especially in mathematics and science, require the following intense and sustained support and systemic program interventions.

1. Early immersion in multiple inquiry-based and problem-centered enrichment opportunities and systemic pathways that foster mathematical and scientific reasoning and promote interpersonal and academic growth. For some academically talented urban youth, engagement over time in multiple and diverse enrichment learning experiences, characterized by a coherent and consistent core, is essential for future success. On IMSA's campus and in locations across Illinois, the IMSA Kids Institute ${ }^{\oplus}$ provides hands-on programs that integrate mathematics and science concepts for students beginning in third grade. Offerings include IMSA on Wheels (an interactive mobile science show), Saturday FUNshops, and summer day camps and residential programs such as Kidsporations in Technology, where fifth and sixth graders learn the basics of robotics, touch-screen technology, and computer programming. The IMSA FUSION program helps upper elementary and middle school students "learn how to learn," emphasizing logic, inquiry, creative problem solving, mathematical reasoning, and experimental scientific thinking.

IMSA PROMISE enables talented underrepresented and economically disadvantaged eighth-grade students to participate in an intense 2-week summer residential experience that stimulates interest in and develops skills in mathematics, science, and the humanities. Ninth-grade students engage in Saturday enrichment programs that integrate mathematics, sci- ence, and English through collaborative research activities, and prepare for the SAT, an important component of the application process to IMSA and to colleges and universities.

These programs form a systemic pathway of options for students to further develop their interests and talents and prepare for advanced study in STEM, at IMSA or elsewhere.

2. A network of significant caring and trusting relationships that help students develop academic confidence and a strong and resilient learning identity. Cultivating supportive individual relationships with like-minded peers, faculty, counselors, and mentors is critical to a student's academic advancement and social and emotional well-being. More fundamental is the institution's intentional creation of a networked constellation of focused support that serves as a "safety net" for students and helps them develop essential competencies and resilience.

Three primary relationships, facilitated by intentional staffing patterns, reduced student-staff ratios, and an institutional commitment to recruit diverse faculty and staff, ground this support network: (a) resident counselors (ratio of 1:24) who reside with the students in the residence halls; (b) faculty (student load of 1:80-90) who regularly mentor, coach, or tutor students requiring additional support and instruction; and (c) career and academic counselors (ratio of 1:160) who help students navigate their programs of study to be congruent with their interests, career preferences, and postsecondary commitments. This network is linked to inquiry and research mentors, community and work service advisors, athletic and cocurricular coaches and sponsors, and a strategy team that meets weekly to analyze and assess the work of specific students and develop support interventions as needed.
3. Multiple opportunities for students to safely explore a wide range of their interests and passions, individually and with others. Students with more vulnerable and often tentative academic identities and self-concepts need opportunities for safe exploration, tinkering, experimentation, and cognitive play. They must be invited and even encouraged to take risks and to fail, especially within the STEM domains, where risk is fundamental to advancement and breakthrough thinking. Academically talented urban youth need a safe and welcoming "practice field" where they can try something "just for the fun of it," and where, in the words of Miguel Garcia, they can delight in safely "blowing something to smithereens!"

Numerous IMSA opportunities provide this opportunity, including (a) nongraded intersession —one week/year where formal classes are supplanted by in-depth engagement in special topics, often conceived and led by students, such as Junk Electronics, Data Compression Techniques, and Cartoonography and World Cultures; (b) nontraditional cocurricular opportunities, such as robotics, where students without an engineering background can work with a team to build a robot; (c) on- and offcampus leadership and service-learning projects that offer opportunities for national and international cultural and educational exchanges and humanitarian projects, such as building homes in Costa Rica; and (4) inquiry, research, and entrepreneurial projects that encourage students to pose their own questions and pursue their authentic interests. Collectively, these individualized forays help students find their voice and their passion.

4. Programs and services that honor students' cultural heritage. Communityand school-based programs and services honor students' cultural heritage, enable them to share it, and foster a 
sense of inclusion, worth, and belonging. Students in Peer Multicultural Educators (PME) foster student learning across all aspects of diversity - ethnic, religious, gender, and socioeconomic. The residential life curriculum focuses on self, self-care, and self in community. Leadership Education and Development (LEAD) inspires students to become positive, ethical leaders who pursue their passions and use their talents to create the change they want to see in the world. They also have opportunities to complete service-learning projects that enhance their understanding of cultures such as annual expeditions to areas of great need with Habitat for Humanity.

In addition, multicultural learning is encouraged through a diverse array of student-initiated clubs; these include the African American Student Association, Alma Latina, Filipino Club, and South Asian Student Association. Through these experiences, students develop the capacities to identify, understand, and accept the rights and responsibilities of belonging to a diverse community.

\section{Conclusion}

Lessons continue to be learned from our students and alumni who offer their counsel on what "kids like them" most need to develop their talents in mathematics and science. Miguel, Lynn, and Terez are no exception.

Miguel emphasizes the importance of building strong parent networks in local communities; he believes it is essential for parents of talented students who have had positive experiences in advanced study programs to share information with other parents of talented students who have not. This is especially critical in cultural groups that historically have not emphasized mathematics and science education or have been reluctant to permit talented children to leave home for advanced study. In the case of Latino parents, Miguel also underscores the importance of hosting Spanish-speaking informational meetings and providing materials in Spanish.

Lynn encourages urban students and their parents to proactively seek and take full advantage of low and nocost programs outside their communities as well as in them. She also emphasizes the importance of ensuring that students have access to an array of classes and experiences as well as early experience in hands-on science.

Terez urges teachers, parents, and other significant adults to make learning more relevant and to help students "see a direct path to what they'll use skills and facts for" so they can answer the question "What can I do with this?" He advocates exposing students to "cool careers they can enjoy and earn money in, like mine, systems architect" and feeding their passion to "design something, create something, and make something concrete." Talented urban youth often "need structure," he said, "so they go down the right path."

It is simply a myth that academically talented children will thrive on their own. This is especially true of those who live and learn in underresourced urban environments, and our nation will pay a price for our inattention. Discovering and developing diverse STEM talent requires commitments manifested in state and national policies focused on addressing the unique needs of academically talented urban youth. It also requires the authentic challenge and support of an intellectually engaging and dynamic learning community that through word and deed encourages them to dream and enables them to flourish. $\mathbf{G C T}$

\section{References}

Chicago Public Schools. (2010). The Chicago Board of Education. Retrieved from http://www.cps.edu/About_CPS/ The_Board_of_Education/Pages/ TheChicagoBoardofEducation.aspx

Illinois Mathematics and Science Academy. (2009). IMSA strategic plan. Retrieved from https://www3.imsa. edu/system/files/Strategic+Plan+Appr oved+July+2009_0.pdf

Illinois Mathematics and Science Academy. (2010). Illinois Mathematics and Science Academy: Section K: Programs for other students. Retrieved from https://www3.imsa.edu/system/files/ Admissions+FUSION+Policy+KA_0.pdf Illinois Mathematics and Science Academy. (n.d.). IMSA FUSION. Retrieved from https://www3.imsa.edu/programs/fusion

Kozol, J. (1991). Savage inequalities: Children in America. New York, NY: Crown.

Martin, D. (2002, September 5). Clement Stone dies at 100; built empire on optimism. The New York Times. Retrieved from http://www.nytimes.com/2002/09/05/ business/clement-stone-dies-at-100-builtempire-on-optimism.html

National Academy of Sciences, National Academy of Engineering, \& Institute of Medicine. (2007). Rising above the gathering storm: Energizing and employing America for a brighter economic future: Executive summary. Washington, DC: National Academies Press.

Obama, B. (2009). Remarks by the President on the "Education to Innovate" campaign. Retrieved from http://www.whitehouse. gov/the-press-office/remarks-presidenteducation-innovate-campaign

Plucker, J. A., Burroughs, N., \& Song, R. (2010). Mind the (other) gap!: The growing excellence gap in $K-12$ education. Bloomington, IN: The Center for Evaluation and Education Policy.

Wyner, J. S., Bridgeland, J. M., \& DiIulio, J. J., Jr. (2007). Achievement trap: How America is failing millions of highachieving students from lower-income families. Retrieved from http://www. civicenterprises.net/pdfs/jkc.pdf 
Reproduced with permission of the copyright owner. Further reproduction prohibited without permission. 